Supporting Information

Comparison of Electrode Structures and Photovoltaic Properties of Porphyrin-Sensitized Solar Cells with $\mathrm{TiO}_{2}$ and $\mathrm{Nb}, \mathrm{Ge}, \mathrm{Zr}$-added $\mathrm{TiO}_{2}$

\title{
Composite Electrodes
}

Hiroshi Imahori, ${ }^{*}{ }^{,}, *$ Shinya Hayashi, ${ }^{\dagger}$ Tomokazu Umeyama, ${ }^{\dagger}$ Seunghun Eu, ${ }^{\dagger}$ Akane Oguro, ${ }^{\dagger}$ Soonchul Kang, ${ }^{\dagger}$ Yoshihiro Matano, ${ }^{\dagger}$ Tetsuya Shishido, ${ }^{\dagger}$ Supachai Ngamsinlapasathian," and Susumu Yoshikawa*,"

$\dagger$ Department of Molecular Engineering, Graduate School of Engineering, Kyoto University, Nishikyo-ku, Kyoto 615-8510, Japan

${ }^{\#}$ Fukui Institute for Fundamental Chemistry, Kyoto University, 34-4, TakanoNishihiraki-cho, Sakyo-ku, Kyoto 606-8103, Japan

'Institute of Advanced Energy, Kyoto University, Uji, Kyoto 611-0011, Japan 


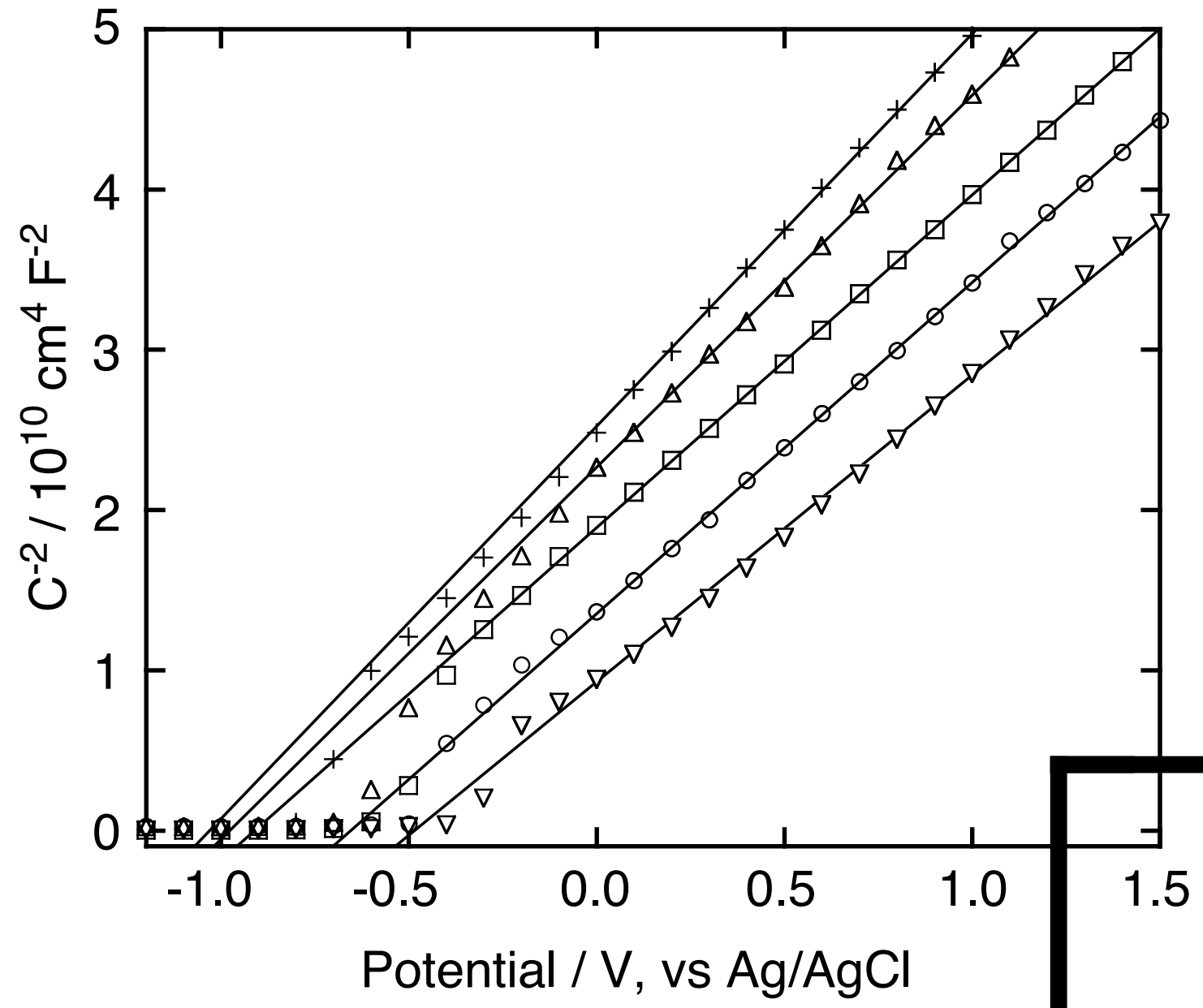

Figure S1. Mott-Schottky plots for the $\mathrm{TiO}_{2}$ electrode at electrolyte $\mathrm{pH}=1.4$ (downward triangle), 4.5 (circle), 9.3 (square), 10.0 (upward triangle), and 10.8 (cross). 


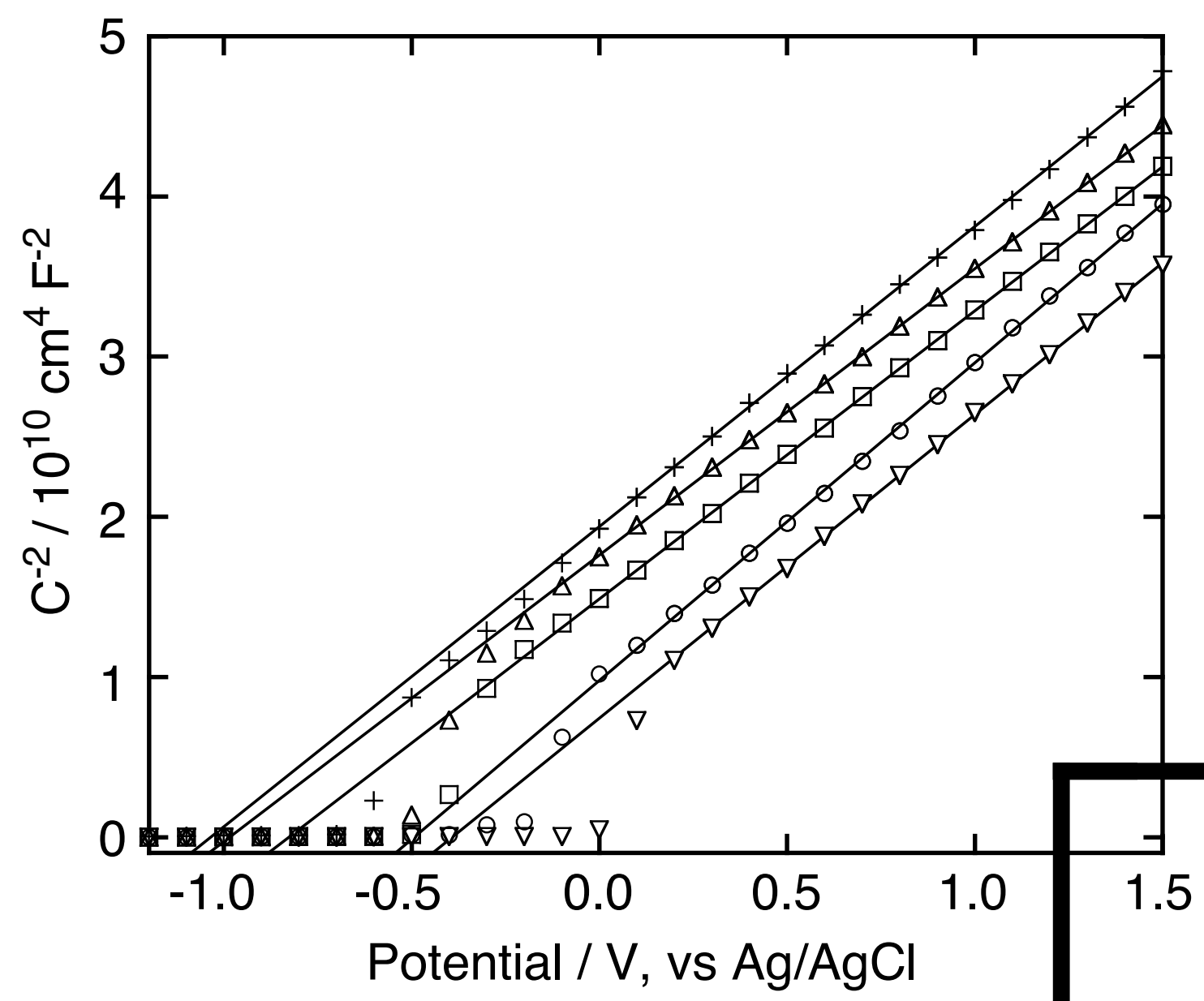

Figure S2. Mott-Schottky plots for the $5 \% \mathrm{Nb}$-added $\mathrm{TiO}_{2}$ electrode at electrolyte pH=2.0 (downward triangle), 4.2 (circle), 9.3 (square), 11.8 (upward triangle), and 12.4 (cross). 


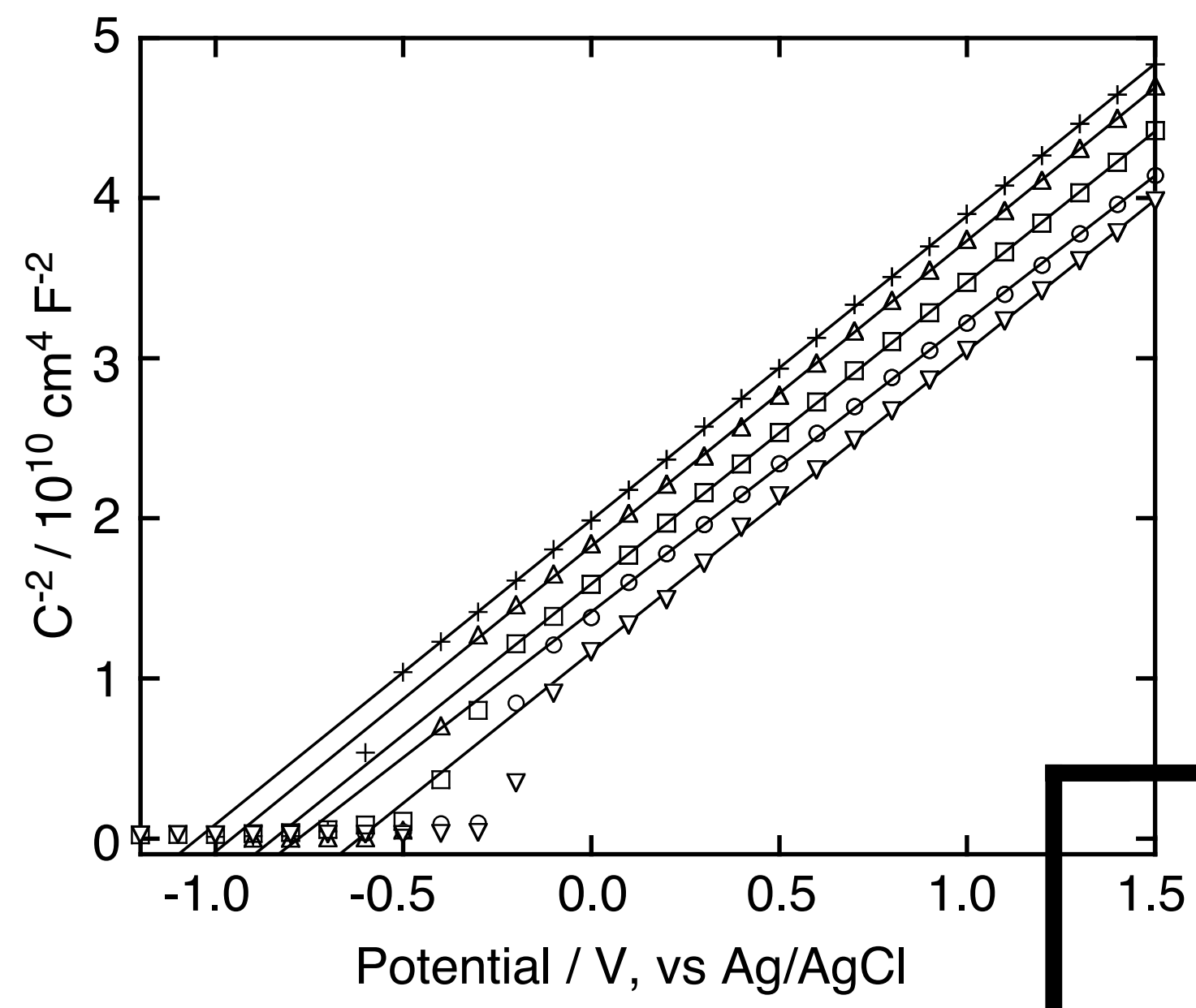

Figure S3. Mott-Schottky plots for the 5\% $\mathrm{Zr}$-added $\mathrm{TiO}_{2}$ electrode at electrolyte pH=2.0 (downward triangle), 3.4 (circle), 5.2 (square), 6.6 (upward triangle), and 9.3 (cross). 